\title{
La dictadura y la radicalización del catolicismo dogmático en Donoso Cortés
}

\author{
Dictatorship and radicalization of dogmatic Catholicism \\ in Donoso Cortés
}

A ditadura e a radicalização do catolicismo dogmático em Donoso Cortés

Fecha de entrega: 10 de diciembre de 2013 Fecha de evaluación: 10 de febrero de 2014

Fecha de aprobación: 16 de marzo de 2014

Diego Paredes Goicochea*

\section{Resumen}

En este artículo, discuto el decisionismo dictatorial de Donoso Cortés, teniendo en cuenta dos hipótesis. En la primera de estas se sostiene que la decisión dictatorial en la filosofía política de Donoso es inseparable de una concepción teológica dogmática. En otras palabras, su reflexión política sobre la dictadura tiene como fundamento una serie de supuestos católicos incuestionados. En la segunda hipótesis se sugiere que es justamente este fundamento católico, que se expresa

* Candidato a doctor en Filosofía de la Universidad Nacional de Colombia y Magíster en Filosofía de la misma universidad. Filósofo de la Universidad de Los Andes. Profesor adjunto de Filosofía, Universidad Autónoma de Colombia. Correo electrónico: adfparedesg@gmail.com 
en una filosofía de la historia pesimista, la que puede llegar a hacer irrelevante la necesidad de la decisión.

Palabras clave: Donoso Cortés, teología política, filosofía de la historia, dictadura política, decisionismo.

\section{Abstract}

In this article. I discuss the dictatorial decisionism of Donoso Cortés, taking into account two hypothesis. The first one sustains that the dictatorial decision in Donoso's political philosophy is inseparable from a dogmatic theological conception. In other words, his political reflection on dictatorship is founded on a series of unquestioned catholic suppositions. On the second hypothesis is suggested that it is precisely this catholic principle, which is expressed in a pessimistic philosophy of history, what can make irrelevant the need of the decision.

Keywords: Donoso Cortés, political theology, philosophy of history, political dictatorship, decisionism.

\section{Resumo}

Neste artigo, discuto o decisionismo ditatorial de Donoso Cortês, considerando-se duas hipóteses. Na primeira delas afirma-se que a decisão ditatorial na filosofia política de Donoso é inseparável de uma concepção teológica dogmática. Em outras palavras, a sua reflexão política sobre a ditadura baseia-se em uma série de suposições católicas não questionadas. Na segunda hipótese sugere-se que é precisamente este fundamento católico, que se expressa em uma filosofia da história pessimista que poderia chegar a fazer sem importância a necessidade da decisão.

Palavras-chave: Donoso Cortês, teologia política, filosofia da história, ditadura política, decisionismo. 


\section{Introducción}

En un artículo de 1929, Carl Schmitt sostuvo que “[...] el papel del seglar aficionado a teología”, asumido por Donoso Cortés, “[...] resultaba ser incompatible con el de teórico de la dictadura política" (Schmitt, 1963, p. 125). Según Schmitt, los éxitos políticos y literarios que Donoso experimentó en vida, sobre todo en el período de 1849 a 1853, fueron paulatinamente ignorados y olvidados a causa de su anticuado estilo literario y lingüístico — cargado de excesivo retoricismo y barroquismo - y el carácter teologizante de su obra principal, expuesto además como dogma y sistema. En esta obra, Ensayo sobre el catolicismo, el liberalismo y el socialismo, "[...] los pasajes grandiosos y arrebatadores se pierden entre prolijas disquisiciones teológicas, apareciendo Donoso como el prototipo del lego metido a teólogo, lo que no fue en sus discursos ni cartas, ni menos aún en su manera de ser" (Schmitt, 1963, p. 124). Aunque en Teología Política I, Schmitt reconoce que Donoso parte de una radicalización del dogma del pecado original, afirma que esta responde a una actitud polémica frente al anarquismo ateo y no a una actitud meramente dogmática.

Así pues, la importancia teórica de Donoso para la historia de las doctrinas antirrevolucionarias no reside, según Schmitt, en su exageración de las doctrinas teológicas, sino en "[...] la consciencia de que su época reclama una decisión [eine Entscheidung verlangt]” (Schmitt, 2009, p. 49). Sin embargo, ¿no está la decisión, cuya radicalización donosiana es la dictadura, fundada en una concepción teológica dogmática?, ¿acaso no depende directamente de los supuestos incuestionados del catolicismo? En otras palabras, ¿es posible separar en Donoso su agudeza política de su pesimismo y desprecio hacia el género humano, basado en su actitud teologizante y en una visión apocalíptica del desarrollo histórico? Teniendo en cuenta estas preguntas, en el presente artículo quisiera someter a discusión dos puntos principales. En primer lugar, intentaré explorar la relación entre teología y política en algunos de los discursos y cartas de Donoso, para mostrar que su defensa de la dictadura no puede ser separada de una radicalización de los principales dogmas del catolicismo. En segundo lugar, intentaré sugerir que el mismo pesimismo de Donoso, fundado en su catolicismo radicalizado, puede llegar a hacer irrelevante la necesidad de la decisión. 


\section{El decisionismo dictatorial como consecuencia del catolicismo dogmático}

La revolución de 1848, que más que un acontecimiento francés o alemán fue europeo, resultó determinante para Donoso Cortés. Schmitt incluso sostiene que la obra del autor español fue un producto del “[...] terror del 48” (Schmitt, 1963, p. 37). Según Donoso, esta revolución de febrero "[...] vino como viene la muerte: de improviso" y no dejó nada firme ni seguro en Europa (Donoso, 1946, p. 191). La repentina caída de la Monarquía Francesa, producto de la insurrección popular, originó un sobresalto y una conmoción que tuvo profundas repercusiones en el pensamiento político de la época. La situación en España era, ciertamente, de asombro y consternación, y fue justamente bajo la estela de este acontecimiento que, el 4 de enero de 1849, Donoso pronunció su discurso sobre la dictadura. En este discurso, la revolución del 48, como toda revolución, es explicada como un suceso providencial, como obra de Dios. Dado que no es un producto de los seres humanos, la revolución no es causada por los defectos de los gobiernos. Hay que estar seguros, dice Donoso, "[...] que las revoluciones vienen del cielo, y que vienen por culpa y para castigo de todos" (Donoso, 1946, p. 192). Sin embargo, cuando ataca los argumentos del partido progresista en lo referente a las causas de la revolución, Donoso prefiere quedarse en el plano de los asuntos humanos y afirma que las revoluciones son enfermedades de los pueblos ricos, de los pueblos libres. El germen de las revoluciones no se encuentra ni en la miseria ni en la tiranía, por el contrario, como lo muestra la historia, las revoluciones se originan a causa de la sobreexcitación de una muchedumbre que, dependiendo de las circunstancias, busca ser como los ricos, los nobles, los reyes o, incluso, los dioses.

La importancia de esta referencia que Donoso hace a la revolución reside no solo en el efecto que aquella de 1848 tuvo sobre su pensamiento, sino además en algo que va más allá: una revolución política es una catástrofe y la del 48 es una amenaza que encendió las alarmas y puso de manifiesto que algo mucho peor estaba por venir. En pocas palabras, las revoluciones son, según Donoso, tormentas que anuncian el triunfo del mal. Con esto, el pensador español advertía hacia dónde consideraba que se dirigía la civilización, pero lo hacía considerando "[...] el conjunto pavoroso de los acontecimientos humanos desde el único punto verdadero: desde las alturas católicas" (Donoso, 1946, p. 197). Según este punto de vista, el mal crece progresiva y lentamente y avanza hacia el momento del diluvio, hacia el ocaso de 
la sociedad. Así, las revoluciones son manifestaciones del castigo que se aproxima, ya que "[...] la sociedad, en definitiva, está herida de muerte; y morirá porque no es católica, y solo el catolicismo es vida” (Donoso, 1946, p. 227). Con esta teología dogmática, Donoso quiso llevar al extremo la oposición entre la revolución y el catolicismo y mostrar que lo que está en juego es una "[...] lucha gigantesca entre el mal y el bien" (Donoso, 1946, p. 208). Es este conflicto, este enfrentamiento entre dos concepciones distintas del mundo - que, para Donoso, definía su época-, lo que exige una decisión.

Ahora bien, según Donoso, el enfrentamiento entre el catolicismo y la revolución no es algo que solo se presenta a partir de los hechos del 48. Lo que quiso señalar era que la revolución hacía parte de una serie de errores que venían creciendo desde el siglo XV, desde el momento en que fue sepultado el siglo de oro de la civilización católica. Por eso, Donoso muestra que, según su perspectiva teológica, el antagonismo absoluto entre el bien y el mal obedece al enfrentamiento entre dos civilizaciones: la católica y la filosófica. La primera es la verdad, la segunda el error. La civilización católica contiene el bien sin la mezcla del mal. Agrega Donoso que la naturaleza del ser humano está enferma y caída en su esencia y que, dada esta naturaleza, si el ser humano intenta inventar o descubrir la verdad, haciendo uso de su propio entendimiento, encontrará únicamente el error. De este modo, la verdad solo puede ser vista por el ser humano cuando es mostrada por Dios. Algo similar sucede con la voluntad, ya que esta solo puede querer el bien si está sujeta y reprimida por el temor divino. La civilización filosófica, por su parte, sostiene justamente lo contario y, por tanto, contiene, según Donoso, el mal sin mezcla de bien alguno. Esta civilización considera que la naturaleza no está enferma, sino entera y sana. Por eso, afirma que el ser humano puede descubrir e inventar la verdad, haciendo uso del sano entendimiento. Pero, además, puede utilizar la propia voluntad para querer bien y obrar bien de manera natural. De este modo, la civilización filosófica, como la presenta Donoso, solo podrá alcanzar su perfección a través de la negación de Dios, tal como lo hace en último término el socialismo ateo.

Donoso no ve ningún punto medio entre estas dos civilizaciones, no hay transacción posible entre estas. Por lo tanto, si alguien resuelve estar por fuera de estas dos alternativas, “[...] anda por los desiertos del vacío” (Donoso, 1946, p. 208). Dado este antagonismo absoluto: 
[...] entre ellas es necesario elegir con una suprema elección, y proclamar en todas sus partes la una, y condenar en todas sus partes la otra, después de haber elegido; los que fluctúan entre ambas, los que de la una aceptan los principios y de la otra las consecuencias, los eclécticos, en fin, están todos fuera de la categoría de las grandes inteligencias y están condenados irremisiblemente al absurdo. (Donoso, 1946, p. 207)

El eclecticismo es aquí inadmisible, así como cualquier intento de síntesis que busque un "tercer término superior". En este caso, la oposición binaria es tan radical que la antítesis solo deja como opción la toma de una decisión suprema. De esta forma, la necesidad de la decisión en el pensamiento de Donoso es inseparable de su concepción del mundo, una concepción que brota directamente de una radicalización del dogma del pecado original. Como se mencionaba anteriormente, el enfrentamiento entre la civilización católica y la filosófica depende, en primera medida, de cómo se concibe en cada caso la naturaleza humana. Donoso insiste que el catolicismo parte del "[...] dogma de la perversión ingénita de la naturaleza humana y de su inclinación hacia el mal" (Donoso, 1946, p. 210). Es el reconocimiento de la naturaleza enferma y caída del ser humano lo que permite a la civilización católica afirmar la grandeza de Dios. Por eso, Donoso insiste que partir del carácter sano de la naturaleza humana, como lo hace la civilización filosófica, conduce necesariamente al desprecio de lo divino. La filosofía proclama la independencia de la razón y de la voluntad del ser humano y, por tanto, convierte al mal en “[...] absoluto, universal, necesario" (Donoso, 1946, p. 212). Según esta perspectiva, este es el rumbo que ha tomado la sociedad. Un rumbo que comenzó con el Renacimiento y ha seguido con la producción del paganismo filosófico, el religioso y el político y terminará, según Donoso, con la insstauración del paganismo socialista. La postulación de este antagonismo radical entre filosofía, Ilustración, revolución, por un lado, y catolicismo, por el otro, constituye, para un pensador como Schmitt, uno de los mayores aciertos de Donoso.

Por lo demás, la singular importancia de Donoso estriba en haber advertido —en una época de relativizadora disolución de los conceptos y antagonismos políticos y en una ambiente de fraude ideológico- la noción central de toda gran política y en haberla mantenido firmemente a través de toda suerte de engañosas y falaces ofuscaciones, tratando de determinar más allá de los distingos propios de la política del día, la grande, histórica y fundamental distinción entre amigo y enemigo (Schmitt, 1963, p. 132). 
La agudeza de Donoso reside, entonces, en haber captado la noción central de toda gran política: la oposición absoluta entre amigo y enemigo. Sin embargo, como lo he tratado de mostrar hasta el momento, dicha oposición solo tiene sentido en el marco de su visión católica. Para apoyar este punto, no solo es necesario detenerse en la concepción de la naturaleza humana que propone el pensador español, sino también en su apocalíptica filosofía de la historia. Después de analizar el aspecto teórico del antagonismo entre civilización católica y civilización filosófica, Donoso afirma que, en la práctica, es solo a esta última a la que le está prometida la victoria: “[... el triunfo en el tiempo será irremisiblemente de la civilización filosófica” (Donoso, 1946, p. 208). La independencia de la humanidad, que se traduce en el uso de la razón y la voluntad sin recurrir a Dios, la aleja del camino de la fe. La historia toma, entonces, otro camino, el camino de la mayor catástrofe, de la barbarie de Europa, ya que "[...] la tierra por donde ha pasado la civilización filosófica será maldecida: será la tierra de la corrupción y de la sangre" (Donoso, 1946, p. 228).

Ahora bien, la naturaleza enferma y caída del ser humano, junto con su rumbo histórico hacia la catástrofe, constituyen el fundamento de la relación que Donoso establece entre teología y política (de hecho, son estos factores lo que le permiten mostrar la necesidad inminente de la dictadura). La relación entre teología y política se evidencia a través del paralelismo presente en la llamada "ley del termómetro". Esta ley, que para Donoso es tanto una ley de la humanidad como una ley de la historia, muestra una relación inversamente proporcional entre la represión religiosa y la represión política: “[...] cuando el termómetro religioso está subido, el termómetro de la represión está bajo, y cuando el termómetro religioso está bajo, el termómetro político, la represión política, la tiranía, está alta” (Donoso, 1946, pp. 197-198).

Donoso intenta exponer la verdad de esta ley apelando a ejemplos históricos. Uno de los más importantes lo da a través de la comparación del mundo antiguo con la época de Jesucristo. En el primero, la represión política llegó a su punto máximo, precisamente porque no había ninguna represión religiosa. Con la llegada de Jesucristo, nació la represión religiosa y la represión política desapareció completamente, al punto que la libertad fue absoluta y la sociedad existió sin necesidad de gobierno. Ahora bien, según este paralelismo, la situación de Europa, después de la revolución del 48, no puede ser más angustiante. En el camino hacia el triunfo de la civilización filosófica, el termómetro religioso está bajo cero, y, por ende, se avecina la victoria del 
despotismo. Entender esta situación es, para Donoso, “[... ] poner el dedo en la llaga; esta es la cuestión de España, la cuestión de Europa, la cuestión de la Humanidad, la cuestión del mundo" (Donoso, 1946, p. 200). De este modo, después del 48, Europa (y la humanidad) no se encuentra en una situación en la que sea posible elegir entre dictadura y libertad. Dado que ha ganado el despotismo, no hay libertad en Europa, y, por tanto, la verdadera elección es entre “[...] la dictadura de la insurrección y la dictadura del Gobierno" (Donoso, 1946, p. 204).

La posición teológica de Donoso extrema el antagonismo entre civilizaciones, para poner de manifiesto que la decisión es ineluctable. Discutir o debatir es eludir la responsabilidad en un momento en el cual lo que realmente está en juego es la salvación de la sociedad. Mientras que el partido progresista privilegia la legalidad en la política interior, Donoso considera que las leyes se han hecho para las sociedades y, en consecuencia, que por encima de todo está la sociedad. Esta primacía de la sociedad sobre la ley corresponde a una del hecho sobre el derecho. Cuando la legalidad no basta para salvar la sociedad, la respuesta es la dictadura (que en esas circunstancias se convierte en un gobierno legítimo, bueno, racional).

La dictadura se justifica, entonces, a nivel teórico, pero también en la práctica, como lo muestra Donoso por medio de ejemplos históricos. Sin embargo, lo más interesante es que la dictadura también hace parte del orden divino. En el "Discurso sobre Europa", Donoso sostiene que hay una relación analógica entre teología y política que explica la superioridad de la monarquía sobre cualquier otra forma de gobierno. La civilización católica, a la que, en este caso, se le da el mote de "civilización afirmativa", considera que existe un dios personal, omnipresente y omnipotente, que reina en el cielo y en la tierra y gobierna absolutamente las cosas divinas y humanas. Así, de manera análoga, en el orden político, existe un rey que está en todas partes y que reina y gobierna sobre sus súbditos (cf. Donoso, 1946, p. 307). En el "Discurso sobre la dictadura”, Donoso también recurre a una analogía entre el orden divino y el político, pero la diferencia es que en este caso ya ni siquiera existe la monarquía y, por eso, la única alternativa es la dictadura. En palabras de Schmitt:

Cuando Donoso Cortés vio que la monarquía tocaba a su fin, porque ni reyes había ya, ni nadie con el valor para serlo sin contar con la voluntad del pueblo, sacó la consecuencia última de su decisionismo [führte er seinen Dezisionismus zu Ende], es decir, reclamó [verlangte] la dictadura política. (Schmitt, 2009, p. 57) 
Sin duda, en el "Discurso sobre la dictadura", Donoso considera que así como Dios puede manifestar "[...] directa, clara y explícitamente su voluntad soberana" y quebrantar las leyes que él mismo se impuso, el soberano puede hacer lo mismo en lo que se refiere al gobierno de las sociedades humanas. En pocas palabras, dado que Dios obra dictatorialmente, el legislador humano también puede hacerlo dependiendo de las circunstancias. Sin embargo, como lo he sugerido a lo largo de esta primera parte, este decisionismo dictatorial solo tiene justificación si las circunstancias se interpretan bajo el dogma teológico que profesa Donoso. Por lo tanto, más allá de una actitud polémica, lo que está en juego es una defensa doctrinal y sistemática de los principios católicos y de sus consecuencias políticas.

\section{El camino hacia la indecisión}

El antagonismo radical entre la civilización católica y la filosófica, entre la civilización afirmativa y la negativa, reclama una intervención autoritaria que evite el triunfo del mal sobre el bien. Sin embargo, esta intervención, que como se ha visto se convierte en Donoso en dictadura, tiene que contar con el hecho de que la historia se aproxima al diluvio, esto es, “[...] al triunfo natural del mal sobre el bien” (Donoso, 1946, p. 209). El énfasis de Donoso es en la palabra natural, ya que, según los principios del catolicismo, basados en la idea de omnipotencia divina y de la flaqueza humana, el hombre no es lo suficientemente poderoso para triunfar sobre el mal. Aquí Donoso quiere ser totalmente consecuente con el dogma católico y, por eso, plantea que la única manera en que las sociedades humanas pueden salir victoriosas en la batalla contra el mal es por medio de la ayuda de Dios y más específicamente a través de la ayuda de su gracia. Por eso afirma Donoso:

Toda mi doctrina está aquí: el triunfo natural del mal sobre el bien y el triunfo sobrenatural de Dios sobre el mal. Aquí está la condenación de todos los sistemas progresistas y perfeccionistas con que los modernos filósofos, embaucadores de profesión, han intentado adormecer a los pueblos, esos niños inmortales. (Donoso, 1946, p. 219)

La verdadera doctrina no es la filosófica que sostiene que el ser humano puede hacer un uso independiente de la razón y de la voluntad, sino la católica que confía su salvación en la influencia milagrosa, esto es, en la gracia. La venida de Jesucristo restableció 
el equilibrio de la libertad humana que había sido roto por el pecado, ya que abrió la posibilidad de la salvación para los seres humanos. Con la llegada del Salvador, el ser humano recobró su libertad primitiva a través de la gracia divina. Por esta razón, el significado del diluvio para la civilización católica no es solo el triunfo natural del mal sobre el bien, sino "[...] el triunfo sobrenatural de Dios sobre el mal por medio de una acción directa, personal y soberana” (Donoso, 1946, p. 209). Entonces, el triunfo sobre mal está reservado a Dios, a un Dios que es “[...] terrible y justiciero".

Sin embargo, ¿qué le queda por hacer al ser humano frente al advenimiento del diluvio? Donoso es claro en señalar que la seguridad del triunfo sobrenatural no puede excusar la lucha humana. Esta lucha puede, por un lado, aplazar la catástrofe. Pero, además, seguir en esta no es solo un deseo del católico, sino un deber conectado con "[...] una recompensa mayor que la victoria" (Donoso, 1946, p. 209). Por eso, aunque el ser humano no pueda triunfar por sí mismo y aunque la victoria dependa del milagro, lo cierto es que esta doctrina no conduce, para Donoso, a la inacción. Pero, estas afirmaciones chocan con aquel tono de pesimismo y desesperanza que recorre las apreciaciones que Donoso hace sobre el rumbo de la historia. Para que la decisión dictatorial tenga algún sentido en el campo del orden político, y no solo en el divino, el legislador humano tiene que advertir la posibilidad de que su elección modifique las circunstancias. Sin embargo, sobre esto Donoso no muestra ningún grado de optimismo. Por ejemplo, en el "Discurso sobre la dictadura", Donoso sostiene que la única manera de evitar la catástrofe es provocando una reacción religiosa que él ve como posible, pero que no cree probable:

\begin{abstract}
Ahora bien, señores: ¿es posible esta reacción? Posible lo es; pero ¿es probable? Señores aquí hablo con la más profunda tristeza; no la creo probable. Yo he visto, señores, y conocido a muchos individuos que salieron de la fe y han vuelto a ella; por desgracia, señores, no he visto jamás a ningún pueblo que haya vuelto a la fe después de haberla perdido. (Donoso, 1946, p. 201)
\end{abstract}

En el campo de los principios, el catolicismo puede sostener la necesidad de la lucha, pero esto no es del todo claro desde la perspectiva de su realidad histórica. El camino hacia siglos de grandes decadencias, el fenecimiento del imperio de la fe, la desaparición de la represión religiosa, el envenenamiento de la sociedad Europea muestran que “[...] de nada sirve rebelarse contra la Providencia, contra la razón y contra la Historia” (Donoso, 1946, p. 221). Así, la visión radicalmente pesimista que Donoso 
tenía del desarrollo histórico, basada sin duda en su misma doctrina católica, puede llegar a ser tan paralizante que, en vez de exigir una elección entre el bien y el mal, termine motivando la indecisión.

\section{Referencias}

Donoso, J. (1946). Obras completas (Vol. 2). Madrid: Editorial Católica.

Donoso, J. (2006). Ensayo sobre el catolicismo, el liberalismo y el socialismo. Granada: Editorial Comares.

Schmitt, C. (1963). Interpretación europea de Donoso Cortés. Madrid: Ediciones Rialp.

Schmitt, C. (2009). Teología política. Madrid: Editorial Trotta. 